\title{
Clinical symptoms of iodine and zinc deficiency in dairy cows
}

\author{
Ivan Nikulin ${ }^{1, *}$, and Ivan Kalyuzhny ${ }^{2}$ \\ ${ }^{1}$ Voronezh State Agrarian University named after Emperor Peter I,Russia, 394087, Voronezh, Michurina \\ ${ }^{2}$ Saratov State Agrarian University named after N. I. Vavilov, Russia, 410012, Saratov, Teatralnaya pl., 1
}

\begin{abstract}
Numerous clinical observations indicate that the silage-concentrate type of dairy cows feeding causes a cascade of pathobiochemical processes occurring by the type of metabolic acidosis, ketosis, hepatosis, with a violation of protein, fat and carbohydrate metabolism. Animals cannot realize the genetically inherent productivity potential.

The culling of cows from the main herd is more than $37 \%$. The main reasons for culling cows are hypo and agalactia as a result of mastitis and ketosis, as well as infertility against the background of repeated infertile inseminations. Allotriophagy, unsteadiness of teeth, resorption of the last tail vertebrae, curvature of the vertebral column, traces of rib fractures, difficulty in lifting and moving when the content of total calcium and inorganic phosphorus in the blood is at the lower limit of physiological values indicate osteodystrophy. Exo-or endophthalmos, myxedema, forelock and mane, disheveled and curly hair, abortions, the birth of premature, ugly, stillborn, sparsely haired or "naked" calves against the background of low levels of protein bound iodine (PBI) in the blood indicate iodine deficiency in their body (hypomicroelementosis J). Coarsening and increased folding of the skin in the area of the head, neck and withers, active keratization on the skin in the area of articular surfaces and croup, thickening of the corolla zone and the border of the hooves in the form of a roller, ski-like growth and deformation of the hoof horn, enlargement and deformation of the joints, decreased reproductive function and low levels of zinc in the blood indicate parakeratosis of cattle (zinc deficiency).
\end{abstract}

Keywords: Swiss cows, clinical symptoms, iodine and zinc deficiency, violation of metabolism.

\section{Introduction}

Disorders of the metabolism of proteins, carbohydrates, lipids, vitamins, micro-and macroelements in highly productive animals are widespread and are one of the leading factors in reducing the efficiency of the livestock industry. The clinical manifestation of metabolic disorders in cattle depends on the deficiency or excess of macro- and microelements, nutrients, the level of dairy or meat productivity, animal housing conditions, the effects of technogenic environmental factors [8].

Numerous clinical observations and biochemical studies indicate that the main causes of metabolic disorders in cows in industrial animal husbandry are: an imbalance in the diet of nutrients and biologically active substances; useof feeds affected by feed mycotoxins; prolonged feeding of acidic monofeeds (silage, haylage, pulp); crowded housing, lack of active exercise and ultraviolet radiation; unsatisfactory microclimate parameters; stress maladaptation [1, 2, 5, 7-12, 15].

The sources of trace elements for animals are feed and, partially, water. The reduced level of trace elements, including zinc, copper and iodine, in soils and groundwater causes their low content in plants, feed and, as a result, their deficiency in the body of animals $[14,16]$. Violations of the technology of harvesting plant feeds and their storage conditions play a role in the loss of vital trace elements $[2,4,10]$. It was found that when the storage conditions were violated, feed lost up to $45-50 \%$ of minerals [4].

The low content of trace elements in animal feed and body is manifested by damage to the backbone, a decrease and perversion of appetite, a decrease in growth, development, productivity, and reproductive ability of animals. Especially severe is the deficiency of trace elements that affects the developing fetus, the viability and subsequent productivity of newborn young animals $[10,13]$. The reduced content of iodine in blood serum, that of copper, zinc, cobalt, and manganese in whole blood indicates their deficiency in feeding diets [8].

Iodine deficiency in humans and animals is a global problem. Under the conditions of total iodine deficiency the normal production of thyroid hormones, which control all types of metabolism, i.e. protein, fat, carbohydrate, macro-and microelement, energy, are disrupted. In this regard, a malfunction of the thyroid gland is accompanied by the development of severe pathobiochemical processes with a clinical manifestation of pathophysiological conditions [ 9].

With iodine deficiency, the intensity of metabolism decreases, the content of sugar, fat, proteins in the blood decreases and the content of intermediate metabolic products - acetone increases; a violation of reproductive function and a rapid decrease in milk productivity in cows is observed [3, 4]. Clinically, iodine deficiency is manifested by the development of myxedema, the appearance of" curly hair"," forelock"," mane", 
disheveled hair, the presence of alopecia, increased dryness and folding of the skin, especially in the neck, exo - and endophthalmos [4]. Highly productive dairy cows are most vulnerable to iodine deficiency during lactation. This is due to the fact that iodine is intensively excreted with milk. It is not by chance that this fact is taken into account and is actively used to obtain naturally iodized milk

Zinc deficiency in the body of animals occurs when its content is low in feed. Zinc deficiency can increase against the background of excessive content of copper, calcium, iron, cadmium, lead, and sulfur in the diet. With zinc deficiency in cows parakeratosis, lameness, ski-like growth and deformation of the hoof horn, thickening of the zones of fringes and corolla in the form of a roller, characteristic of a severe form of zinc deficiency are observed [4]. In order to attract the attention of managers and specialists of livestock farms, including scientific researchers, to the problem of iodine and zinc deficiency in cows, we present the results of clinical studies.

The aim of the study was to identify changes in the clinical status and hematological profile in dairy cows with iodine and zinc deficiency.

\section{Materials and methods}

The work was performed under the conditions of the dairy farm of the department "Kolos" of LLC "Agricultural Enterprize "Vyazovo" of Efremovsky District of Tula Region in the period from 05.11.2018 to 17.05.2019. The object of the study was sex-and-age cows $(n=200)$ of the main dairy herd of Swiss breed in various physiological conditions.

The assessment of the health status of cows was carried out according to the results of medical examination according to the generally accepted methodology [6]. The medical examination included the analysis of the production indicators of the cattle breeding industry, the conditions of feeding and keeping cows and calves, an inspection of the entire livestock of animals, a complete clinical study of the cows of control groups, a laboratory study of blood, urine and milk samples.

As objects for biochemical studies, dry cows were used 30-15 days before the planned calving $(n=4)$; newly calved cows from 14 days after calving $(n=3)$; lactating cows from 6 to 7 months of lactation $(n=13)$.

The clinical study of animals was carried out according to the scheme generally accepted in veterinary practice [6]. During the examination, special attention was paid to fatness, the condition of the hair, skin, hooves, visible mucous membranes, bone (ribs, transverse branches of the lumbar vertebrae, the last tail vertebrae and limb joints).

Laboratory tests of blood, urine and milk were carried out according to generally accepted methods using a modern and certified equipment in the Efremov Interdistrict Veterinary Laboratory and in the All-Russian Scientific Research Veterinary Institute of Pathology, Pharmacology and Therapy [8].

\section{Results and Discussion}

LLC AE "Vyazovo" uses feeds of its own production for feeding cows (corn silage, haylage of Sudanese grass, bromegrass hay, winter wheat straw, grain waste) and imported (rapeseed cake, feed molasses, table salt, feed chalk, Felucene lick). In the structure of feed consumption for lactating cows in the housing period, concentrated feed makes up $38 \%$, silage $21.4 \%$, haylage $15.8 \%$, molasses $-12.5 \%$, hay $-12.3 \%$; for dry down-calving cows silage- $33.1 \%$, straw- $25.3 \%$, hay- $23 \%$, concentrates$13.2 \%$, molasses $-5.3 \%$. In terms of energy nutrition, the diet corresponded to the needs of the body of milking cows and was deficient by $32.6 \%$ in dry cows. Diets are unbalanced in terms of basic nutrients. There is an excess of dry matter by $5.9 \%$ and $70.2 \%$, respectively, in the diets of milking and dry cows.

In the diet of lactating cows, lysine deficiency is $46.1 \%$, tryptophan $46.6 \%$, starch $12.9 \%$ and an excess of methionine $18.0 \%$, sugar and crude fat, respectively, 51.0 and $69.1 \%$. The diet is also unbalanced in terms of trace elements and vitamins: there was a lack of zinc by $24.5 \%$, cobalt by $20.9 \%$, iodine by $30.8 \%$, vitamin D by $61.6 \%$ and an excess of copper by $31.8 \%$, calcium by $38.9 \%$, manganese by $51.2 \%$, magnesium by $67.7 \%$ and a significant excess of the needs of the animal body in potassium (3.4 times), iron ( 7.9 times) and vitamin E (2.9 times).

In the diet of dry cows, the lack of lysine and tryptophan was 35.8 and $62.3 \%$, starch $48.2 \%$, phosphorus and copper 45.7 and $31.2 \%$ with an excess of zinc $10.3 \%$, iodine $19.0 \%$, iron $23.6 \%$, manganese $44.1 \%$, magnesium 2.2 times, potassium 3.1 times, vitamins D and $E 4.3$ and 2.7 times, respectively, with a lack of carotene by $29.0 \%$.

According to the results of the medical examination, the greatest share in the structure of obstetric and gynecological pathologies of the seedstock herd is subclinical and clinical mastitis (respectively in 64 and $22 \%$ of animals), acute puerperal endometritis (23.8\%), $18.8 \%$ of animals have ovarian hypofunction and uterine hypotension, $12.6 \%$ have persistent yellow body, $7.4 \%$ have ovarian cysts. The retention of the afterbirth was in $8.8 \%$ of calved cows. Abortions are not uncommon $(2.4 \%)$, up to $4 \%$ of calves are stillborn, there are cases of deformities, the birth of premature, "naked" or "rarehaired" calves (Fig. 1).

$3 \%$ of cows were found to have exo- or endophthalmos (Fig. 2-3), 4\% of cows had mucosal edema of the intermaxillary space (Fig. 4-5).

In $4 \%$ of cows disheveled and curly hair was found (Fig. 6), in 6\% "forelock" and "mane" of coarse long hair (Fig. 7 and 8), in $41 \%$ parakeratosis of the skin in the joints and croup, and in $29 \%$ in the head, neck and withers (Fig. 9 and 10). In $26 \%$ of cows, increased skin folding in the neck area was noted (Fig. 11 and 12), in $11 \%$ thickening of the corolla zone and the hoof border in the form of a roller (Fig. 13 and 14), in 6.5\% - ski-like growth and deformation of the hoof horn (Fig. 15 and 16), in 4.5\% enlargement and deformation of the joints, in $6 \%$ curvature of the vertebrae. Exo-or endophthalmos, 


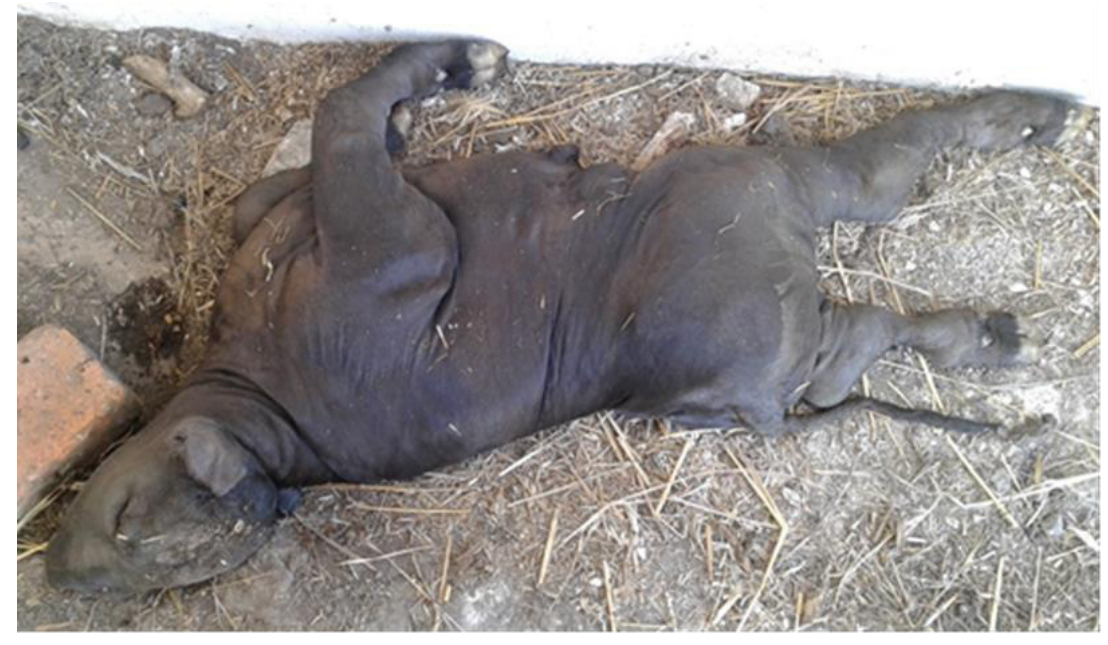

Fig. 1. An ugly rare-haired calf born dead at term

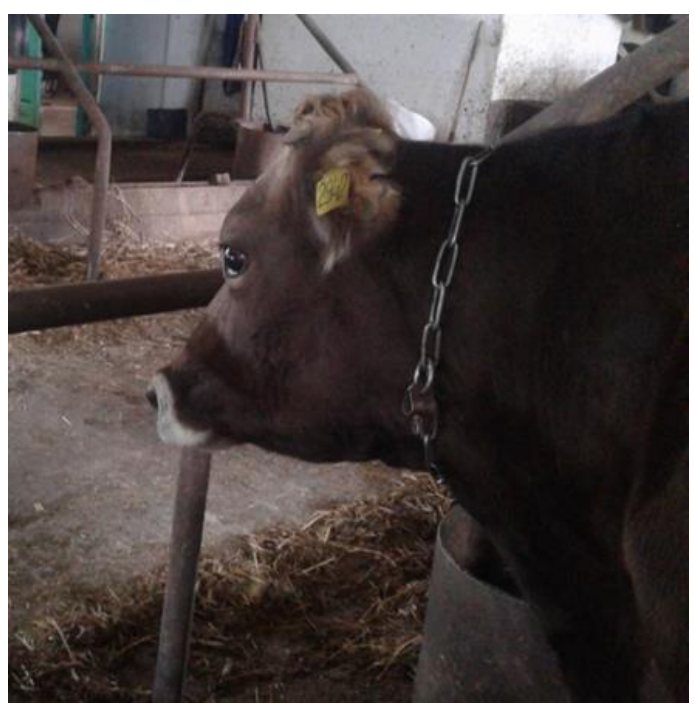

Fig. 2. Exophthalmos in a cow

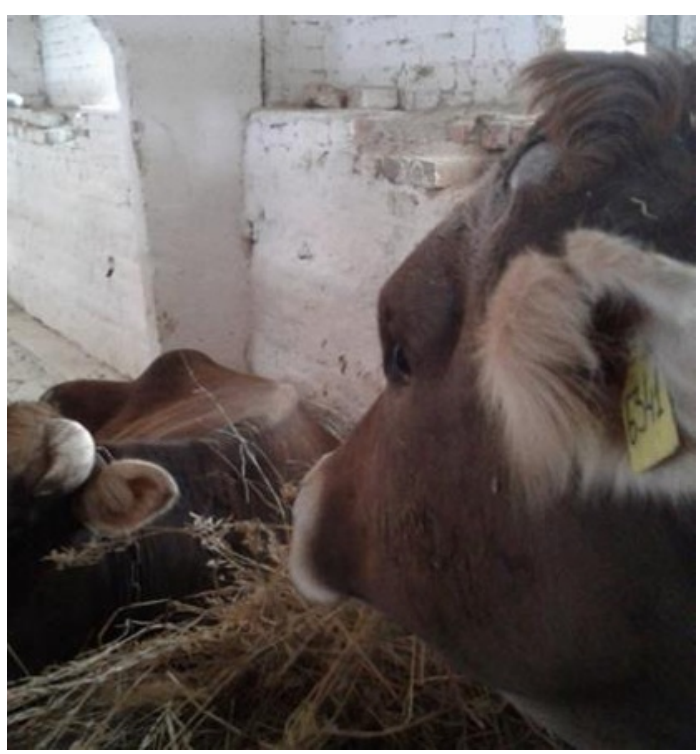

Fig. 3. Oenophthalmos in a cow
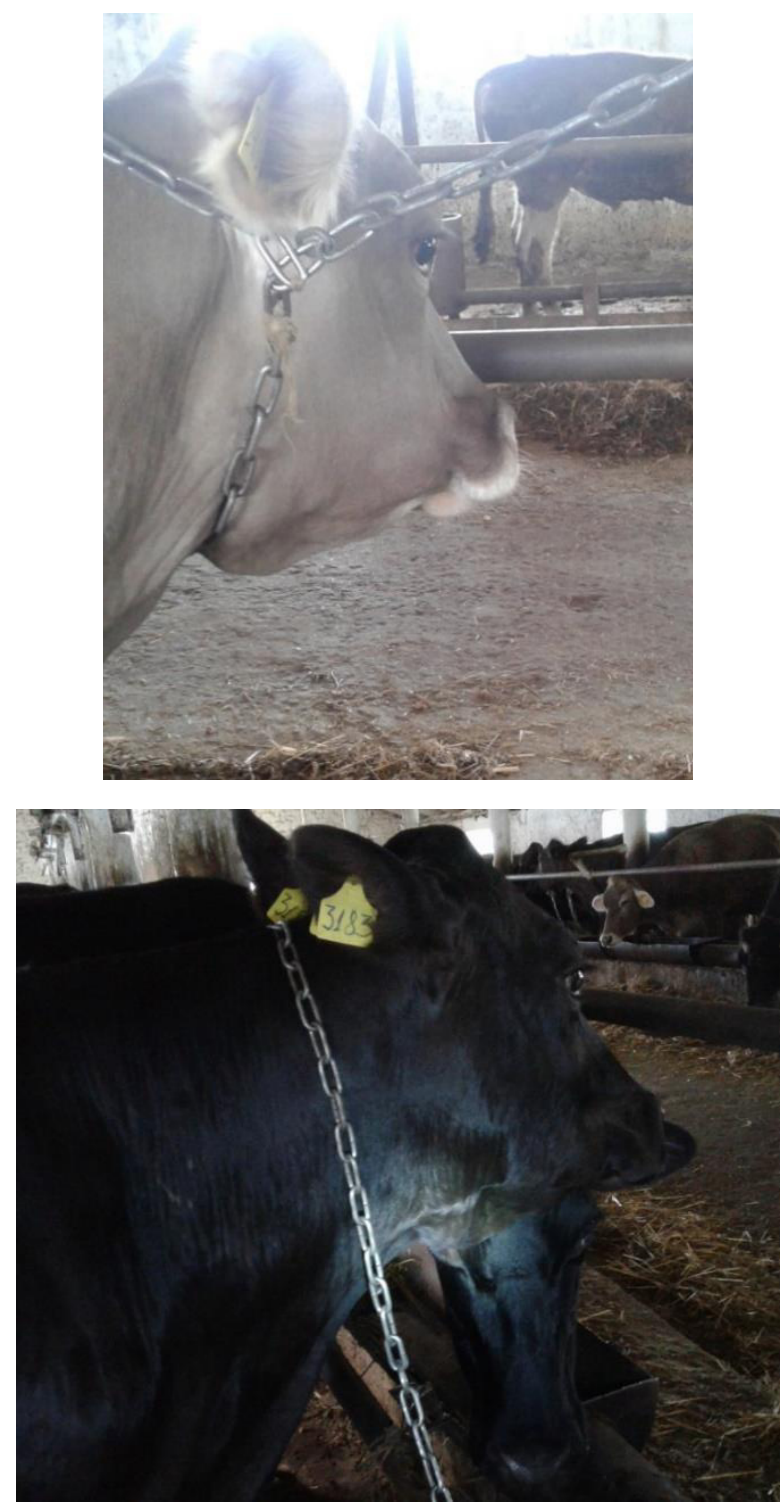

Fig. 4 and 5. Myxedema (swelling of the intermaxillary space) in cows 


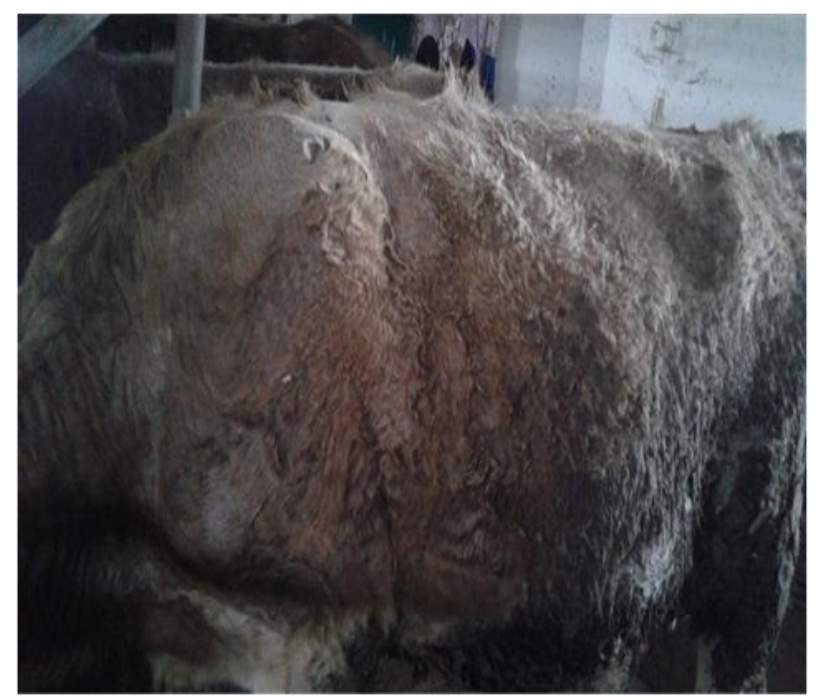

Fig. 6. Disheveled and curly hair of a cow
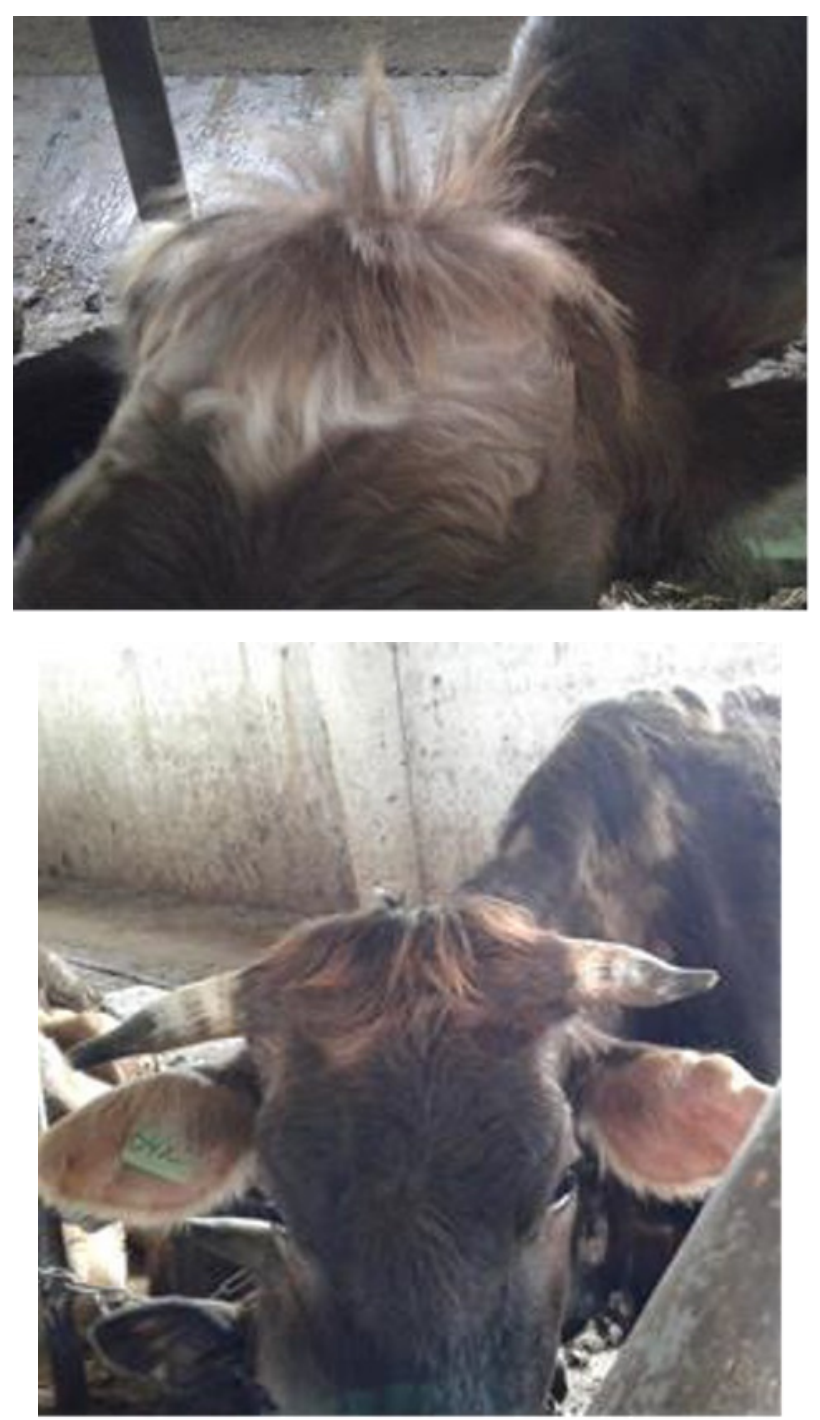

Fig.7 and 8. "Forelock" and "mane" of long and coarse hair in cows
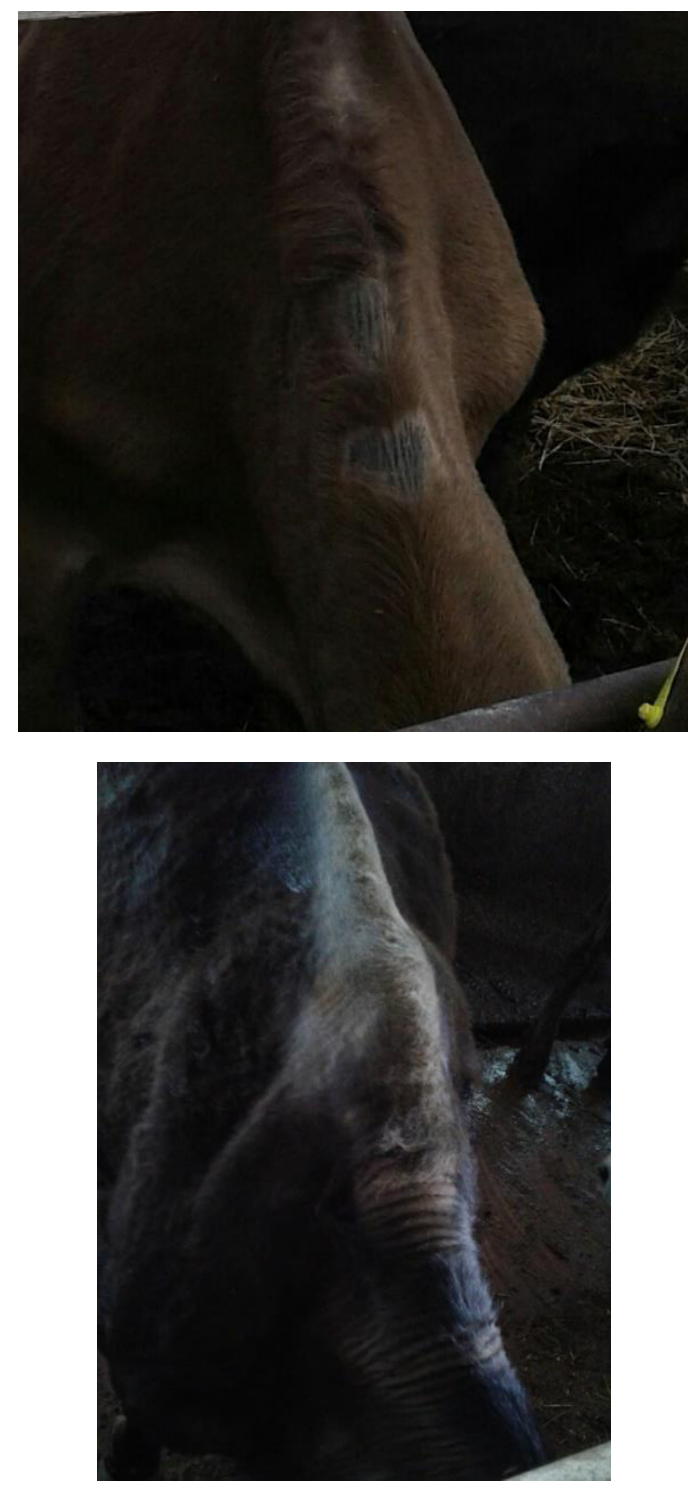

Fig. 9 and 10. Coarsening and loss of elasticity of the skin in the neck and withers in cows

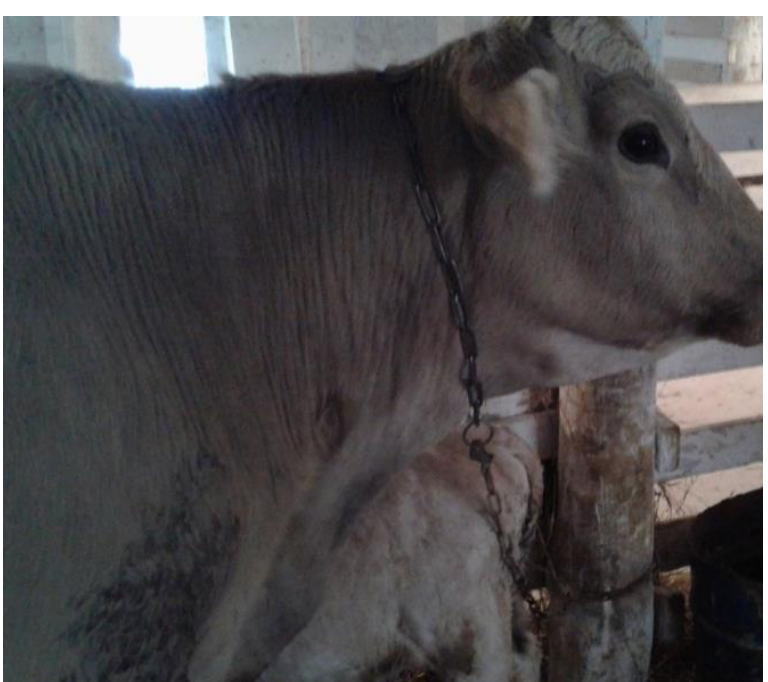




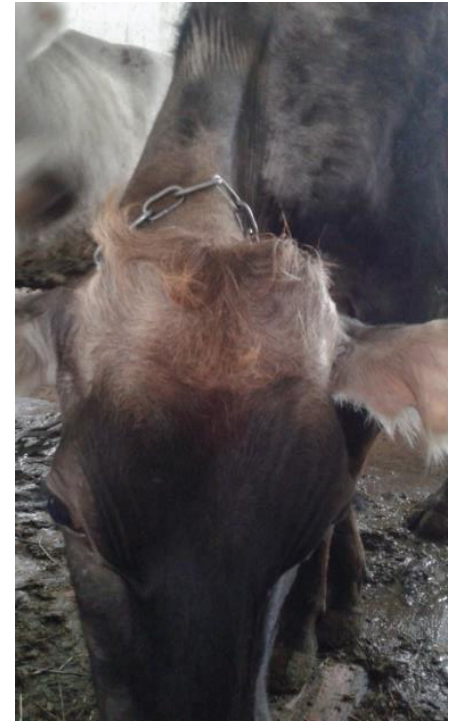

Fig. 11 and 12. Increased skin folding in the neck area in cows
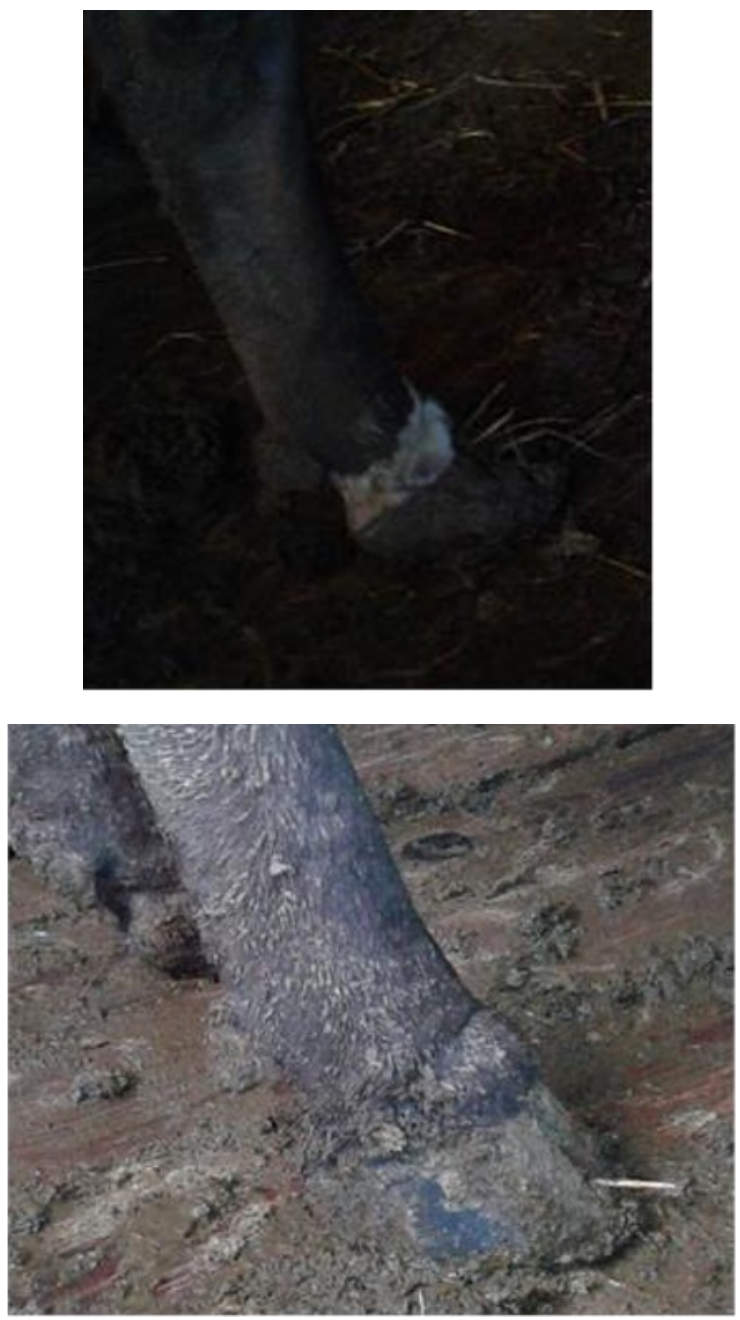

Fig. 13 and 14. Thickening of the corolla zone and the hoof border in the form of a roller in cows
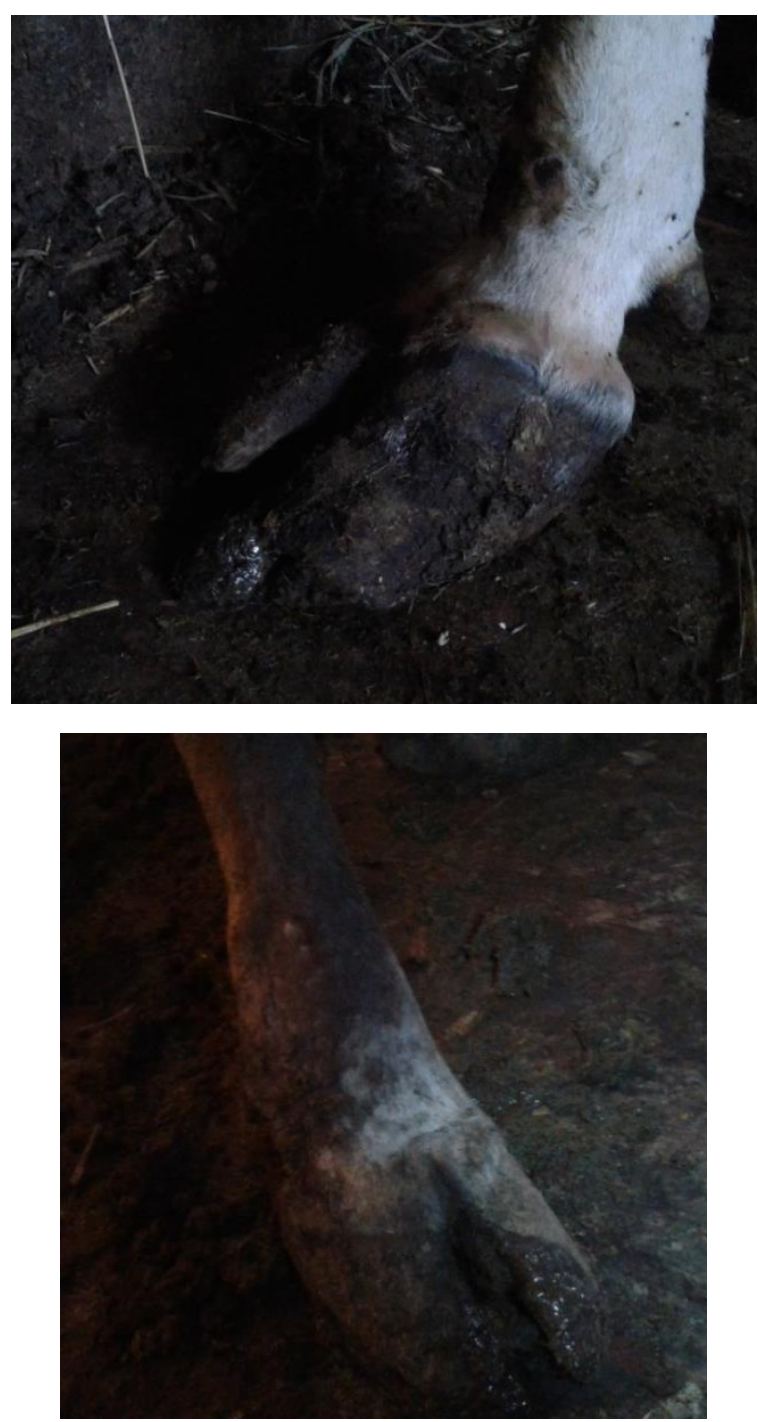

Fig. 15 and 16. Like growth and deformation of the hoof horn in cows

myxedema, forelock and mane, disheveled and curly hair on the background of a low level of PBI in the blood indicate iodine deficiency in their body (hypomicroelementosis $\mathrm{J}$ ).

Coarsening and increased folding of the skin in the area of the head, neck and withers, active keratization of the skin in the area of the joints and croup, thickening of the corolla zone and the border of the hooves, ski-like growth and deformation of the hoof horn, enlargement and deformation of the joints, decreased reproductive function and low levels of zinc in the blood, indicate parakeratosis of cattle (zinc deficiency). In 12\% of cows kyphosis or lordosis was found to be of varying severity (Fig. 17 ), in $25 \%$ resorption of the last tail vertebrae for $10-15 \mathrm{~cm}$ and in $7 \%$ for more than $15 \mathrm{~cm}$ (Fig. 18), in 3\% difficulty in lifting and moving, which may indicate osteodystrophy 


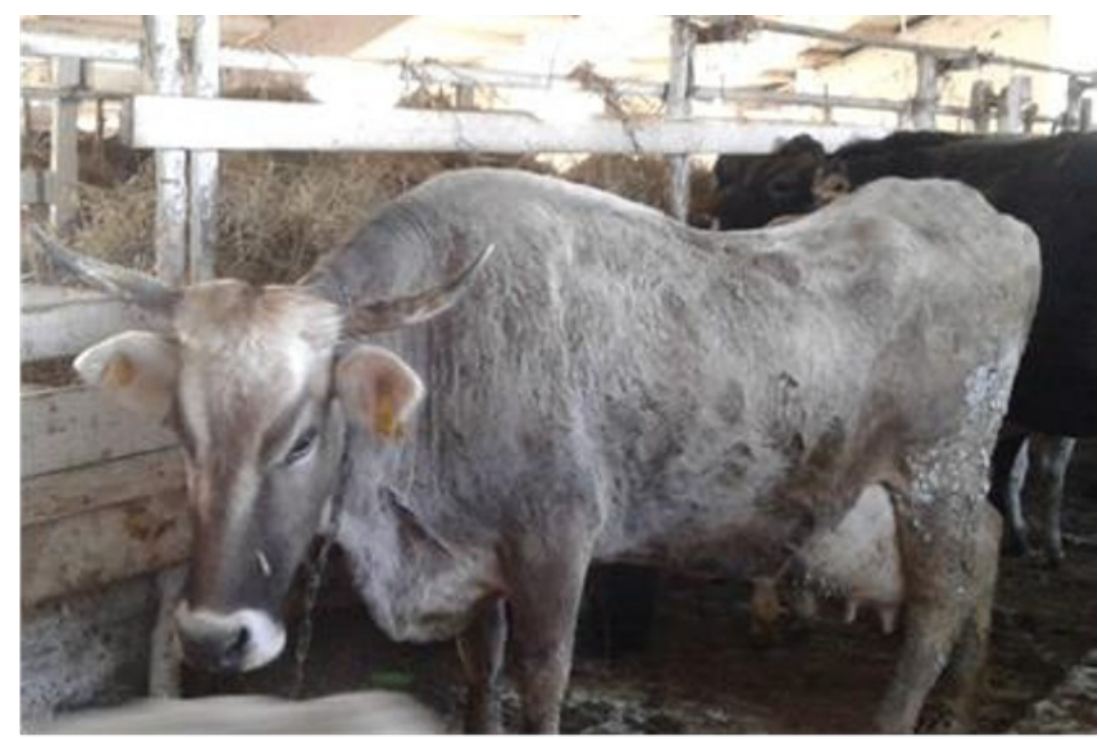

Fig. 17. Lordosis in a cow

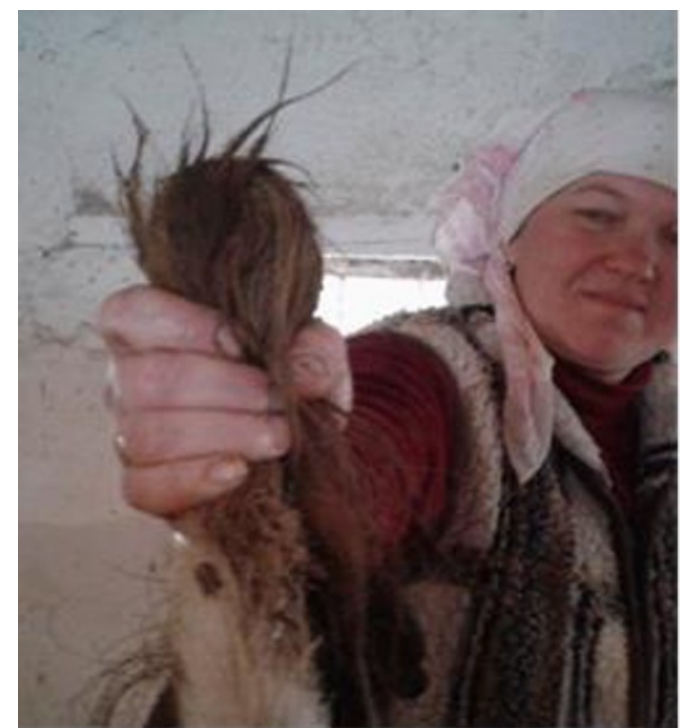

Fig. 18. Resorption of the last tail vertebrae

In a clinical study of cows of the control groups, it was found that the body temperature, heart rate and respiration in the studied animals are within the physiological parameters.

In $66 \%$ of newly calved and $50 \%$ of down-calving cows, there is shakiness of the teeth, which indicates a violation of mineral metabolism. The displacement of the posterior border of the liver to a moderate degree was found in $33 \%$ of newly calved and $8 \%$ of lactating cows, which indicates the development of hepatosis. Indistinctness and splitting of heart tones were detected in $33 \%$ of newly calved and $8 \%$ of lactating cows, which indicates myocardiodystrophy and may be the result of inadequate feeding of animals.

Preventricular hypotension was found in 50\% of dry, $33 \%$ of newly calved and $15 \%$ of lactating cows (less than 6 paunch contractions per 5 minutes), which also indicates errors in their feeding. Signs of emphysema of the lungs were detected in $66 \%$ of newly calved, $25 \%$ of dry and $8 \%$ of lactating cows.
A laboratory study of urine and milk revealed a positive Lestrade test in $66 \%$ of newly calved and $15 \%$ of lactating cows, which directly indicates the development of ketosis in these production groups.

Laboratory blood tests revealed that the content of total calcium and inorganic phosphorus in all isolated groups of animals was at the lower limit of physiological parameters, respectively, $2.58-2.61 \mathrm{mmol} / 1$ and 1.68 $11.97 \mathrm{mmol} / \mathrm{l}$; there is a low level of zinc (98.4-102.5 $\mathrm{mcg} \%)$ and protein-bound iodine $(1.08-2.19 \mathrm{mcg} \%)$.

\section{Conclusion}

Based on clinical observations and biochemical studies, it was found that with iodine and zinc deficiency cows develop a cascade of pathobiochemical processes occurring according to the type of ketosis, hepatosis, with the clinical development of symptoms of emphysema of the lungs, myocardiodystrophy, hypotension of the preventricles, with the manifestation of symptoms of osteodystrophy, allotriphagy, exophthalmos, with skin lesions and hair disorders, joint pathology.

\section{References}

1. G.I. Gorshkov, V.V. Dronov, Clinical and laboratory diagnostics of hypomicroelementosis of cattle in the farms of Belgorod region, in: Problems of agricultural production at the present stage and ways to solve them (2011)

2. I.M. Donnik, P.N. SmirnovI. M. Ecology and animal health (Publishing and Editorial Agency UTK, Yekaterinburg, 2001)

3. V.V. Dronov, Vet. Bull., 6 (2006)

4. V.V. Dronov, G.I. Gorshkov, Methodological guide for the diagnostics of zinc, copper and iodine deficiency in the body of cattle (FGOU VO Belgorod State University, Maysky settl.(2018) 
5. V.V. Dronov, E. G. Yakovleva, M. O. Alexandrova, T. A. Ilyina, Monitoring of the availability of trace elements of the cattle organism in the geochemical zones of Belgorod region, in: Problems of agricultural production at the present stage and ways to solve them, Materials of the International Scientific and Industrial Conference (2012)

6. S. P. Kovalev, A. P. Kurdeko, K. H. Murzagulov, et al., Clinical diagnostics of internal diseases of animals, Tutorial (Publishing House "LAN", St. Petersburg, 2019)

7. Yu. N. Alekhin, S. V. Shabunin, M. I. Retski, et al, Guidelines for the diagnostics, prevention and treatment of hepatopathy in cattle ("Skoropechatnya", Voronezh, 2009)

8. M. I. Retsky, A. G. Shakhov, V. I. Shushlebin, Methodological recommendations for the diagnosis, therapy and prevention of metabolic disorders in productive animals (Istoki, Voronezh, 2005)

9. A.A. Yevglevsky, V.N. Skira, G.F. Ryzhkova, I.I. Mikhailova, Bull. Russ. Agr. Sci., 2 (2019)

10. V.T. Samokhin, Prevention of disorders of the metabolism of trace elements in animals (Voronezh State University, Voronezh, 2003)

11. Ecological and adaptive strategy for protecting the health and productivity of animals under modern conditions (Voronezh State University, Voronezh, 2001)

12. A. Ianni, D. Innosa, C. Martino, et al., J. Dairy Sci., 102, 4 (2019)

13. J. J. Wichtel, A. L. Craigie, D. A. Freeman, et al, J. Dairy Sci., 79, 10 (1996)

14. 14. Vahid Noaman Received, Comp Clin Pathol, 23 (2014)

15. C.M. Cope, A. M. Mackenzie, D. Wilde et al., J. Dairy Sci., 92, 5 (2009)

16. I. Davidov, M. Radinović , M. Erdeljan, et al. Acta Sci. Vet., 42 (2014) 